\title{
Interannual and interdecadal variability of atmospheric synoptic-scale activity in the Southern Hemisphere
}

\author{
Carolina Vera \\ CIMA/Department of Atmospheric and Ocean Sciences, University of Buenos Aires-CONICET, Buenos Aires, Argentina
}

Received 4 April 2000; revised 10 April 2001; accepted 10 September 2001; published 4 January 2003.

[1] A rotated empirical orthogonal function analysis was applied to anomalies of July atmospheric short time scale variability (or storm tracks) over the Southern Hemisphere (SH) using NCEP reanalyses. The study reveals the existence of two leading modes of storm-track variations, the first one describing storm-track changes along the subtropical Pacific and the second one associated with variations over southeast Pacific Ocean. The principal components of both modes exhibit significant variability on interannual (2-7 years) and interdecadal (longer than 7 years) time scales. The interannual variation of the first mode is closely linked to ENSO variability. The corresponding signal on SST anomalies shows a conspicuous maximum over central equatorial Pacific, while the signature on geopotential-height anomalies shows the typical Pacific South America pattern characterized by a Rossby wave train propagating poleward from the tropics. On interdecadal time scales, the first mode is related to SST anomalies over the subtropical portions of the Pacific, Atlantic, and Indian Oceans and to a Rossby wave train with strongest signals over the southeast Pacific and the Antarctic Peninsula. The second mode that represents storm-track changes west of the Antarctic Peninsula is related on interannual time scales to SST anomalies over western Pacific between $40^{\circ} \mathrm{S}$ and $20^{\circ} \mathrm{S}$, while on interdecadal time scales, it does not seem to be significantly related to SST changes in any of the basins. In particular, the spatial signature of the REOF2 interdecadal variability on the SH circulation corresponds to the well-known high latitude mode characterized by a monopole over the Antarctica and a three-wave pattern at middle latitudes. INDEX TERMS: 3319 Meteorology and Atmospheric Dynamics: General circulation; 4215 Oceanography: General: Climate and interannual variability (3309); 3364 Meteorology and Atmospheric Dynamics: Synoptic-scale meteorology; KEYWORDS: storm tracks, Southern Hemisphere, interannual variations, interdecadal variations, synoptic-scale variability

Citation: Vera, C., Interannual and interdecadal variability of atmospheric synoptic-scale activity in the Southern Hemisphere, J. Geophys. Res., 108(C4), 8077, doi:10.1029/2000JC000406, 2003.

\section{Introduction}

[2] Extratropical atmospheric variability responsible for much of the weather in middle and high latitudes arises primarily from the passage of cyclones and anticyclones and their associated frontal systems. These fluctuations exhibit periods of less than 10 days (synoptic scales) and it is widely recognized that they arise through baroclinic instability of the mean flow. Regions where high-frequency variability maximizes are known as storm tracks and it is well known that they explain a large percentage of Southern Hemisphere (SH) total transient variance [Trenberth, 1991]. Storm-tracks attain their largest values at upper-tropospheric levels and during austral winter they span along the $50^{\circ} \mathrm{S}$ over both the South Atlantic and Indian Ocean while over the Pacific Ocean, more intense values are observed along both subpolar and subtropical jet latitudes [Berbery and

Copyright 2003 by the American Geophysical Union. 0148-0227/03/2000JC000406\$09.00
Vera, 1996, Figure 1]. In particular, the subtropical stormtrack over the Pacific Ocean is an austral winter feature while the subpolar storm-track and the maximum over the Indian Ocean prevail all year-round [Trenberth, 1991].

[3] $\mathrm{SH}$ atmospheric circulation exhibits meaningful patterns on interannual and interdecadal time scales [Kidson, 1999, and references therein] that would modulate the synoptic-scale activity mainly through changes in the basic state where waves are embedded. However, the variability of the SH storm tracks on interannual and longer time scales have not been extensively studied yet, maybe due to the lack of reliable and long records of data. Recently, available reanalysis data sets, produced with frozen data assimilation systems, provide an excellent opportunity to address those issues. Using NCEP reanalyses, Solman and Menendez [2000] documented that winter SH storm-tracks have significant changes between warm and cold events of El NiñoSouthern Oscillation (ENSO). During warm events, the subtropical storm-track over the Pacific Ocean gets weaker, while, during cold events the double-jet structure tends to be 
more prominent and an enhancement of the synoptic-scale activity is observed over the Pacific Ocean between $30^{\circ} \mathrm{S}$ and $60^{\circ} \mathrm{S}$. In agreement, Yuan et al. [1999] found opposite synoptic-scale wave anomalies in the South Atlantic and South Pacific in late 1996 - a La Niña period). Furthermore, Sinclair et al. [1997] documented that during ENSO warm events, over $20 \%$ more cyclones occur in a broad band extended southeastward from the subtropical Pacific toward South America. Marshall and King [1998] found that cold (warm) winter temperature anomalies over the Antarctic Peninsula are associated with a decrease (increase) of the cyclone tracks passing across the South Pacific Ocean. For longer time scales, Simmonds and Keay [2000b] have found that during the period 1958-1997, cyclone density has undergone reductions at most locations south of about $40^{\circ} \mathrm{S}$ and increases to the north, resembling the "high latitude mode" identified in many studies of SH circulation features [Kidson, 1999]. Moreover, Chen and Yen [1997] identified interdecadal variations of cyclone activity at $\mathrm{SH}$ subpolar latitudes during winter associated with a zonal wave number 3 pattern at high middle latitudes.

[4] Therefore, in this paper, low-frequency patterns of SH winter storm-track variations are identified and related with the better known modes of mean circulation variability on interannual and interdecadal time scales. The paper is structured as follows. In section 2, we describe the data sets and methodology. Mean circulation features of the $\mathrm{SH}$ winter are briefly presented in section 3.1, while in section 3.2 the leading REOF modes of storm-track variability are discussed. The spatial signatures of the two leading modes, in sea surface temperature and SH circulation, are presented in sections 3.3 and 3.4 respectively. We conclude with an outline of the main results in section 4 .

\section{Data and Methodology}

[5] The primary data used in this study are daily averaged fields from NCEP-NCAR reanalyses for the July months of the period $1965-1999$ on a $2.5^{\circ} \times 2.5^{\circ}$ latitude-longitude grid. Full details of the NCEP-NCAR project and the data set are given by Kalnay et al. [1996] and discussions about its quality over the $\mathrm{SH}$ can be found, for example, in the studies of Garreaud and Battisti [1999] and Simmonds and Keay [2000a]. One of the errors that must be kept in mind is the misallocation of surface pressure bogus data (PAOBs) at SH high-latitudes between 1979 and 1992 that would most affect submonthly variability (http:/wesley.wwb.noaa.gov/ paobs/paobs.html). Simmonds and Keay [2000a] made a detailed examination of this error impact on $\mathrm{SH}$ circulation statistics and they showed that it has a negligible impact on surface cyclone climatology. Nevertheless, to assure that our results are not influenced by the PAOBs problem, all calculations were also performed using daily 1200 UTC reanalyses from European Centre for Medium-Range Weather Forecasts (ERA) available for the period 19791993. The sea surface temperature (SST) July means from NCEP reanalyses are also used in this study. This data set includes Reynolds SST analyses [Reynolds and Smith, 1994] from 1982 onward and UK Meteorological Office SST fields [Folland and Parker, 1995] for previous years. The CPC Merged Analysis of Precipitation (CMAP) data set was also used that consists of monthly averaged precip- itation rate values from 5 different kinds of satellite estimates for the period 1979-1999.

[6] The $300-\mathrm{hPa}$ meridional wind perturbation $\left(v^{\prime}\right)$ was chosen in our study as the key variable to represent shorttime scale perturbations. As in the studies of Berbery and Vera [1996] and Vera and Vigliarolo [2000], $v^{\prime}$ is defined as deviations of daily values from their corresponding longterm daily mean and from the corresponding monthly anomalies of each individual year, removing in that sense, the seasonal cycle and any interannual variability from the series. No further filtering was performed to isolate short time scale variability, since there is evidence that meridional wind variability in $\mathrm{SH}$ extratropics is concentrated in the higher frequencies [Trenberth 1981]. The standard deviation of the 300-hPa meridional-wind perturbation was computed for each individual July and considered as a monthly quantity of the synoptic-scale variability (hereafter referred as storm-tracks). In that sense, the mean storm-track is calculated averaging over all the July $v^{\prime}$ standard deviations while storm-track monthly anomalies are defined as the difference between each individual standard deviation and the mean storm-track.

\section{Results}

\subsection{Basic Fields}

[7] Figure 1a shows the mean $300-\mathrm{hPa}$ storm-tracks calculated from ERA. Over the Atlantic and Indian Oceans, enhanced short-time scale activity concentrates in a band along the $50^{\circ} \mathrm{S}$ while along the Pacific Ocean, storm tracks exhibit large values along both subtropical and subpolar latitudes. Berbery and Vera [1996] have shown that the SH winter storm-tracks are linked to the regions of mean baroclinicity that exhibit maximum values beneath the subpolar jet from South America toward Antarctica and along the subtropical jet latitudes over the South Pacific Ocean (their Figure 1). Low-level meridional heat transports also from ERA (Figure 1c) are poleward along the whole hemisphere with greatest values located to the entrance and over the Indian Ocean storm-track and also over southeastern Pacific, indicating that waves evolving those regions have the most favorable shape to grow by baroclinic conversions. A comparison with the same fields calculated using NCEP reanalyses was done. Although both stormtracks and meridional heat transports from NCEP data (Figures $1 \mathrm{~b}$ and $1 \mathrm{~d}$, respectively) present lower values than those obtained using ERA, their patterns are essentially the same and seem to not be strongly affected by the PAOBs problem.

\subsection{REOF Analysis}

[8] In order to identify the leading patterns of storm-track low-frequency variations, a rotated empirical orthogonal function (REOF) analysis was applied to storm-track anomalies (as defined in section 2) along a latitudinal channel between $80^{\circ} \mathrm{S}$ and $20^{\circ} \mathrm{S}$. First, the analysis was calculated using both ERA and NCEP data for the period from 1979 to 1993. The first two REOFs (not shown) were essentially the same for both data sets, displaying similar spatial patterns and similar variability of their corresponding temporal coefficient series. Therefore, we decided to obtain the leading modes using a more extended period of the 


\section{JLY $(1979-1993)$}

(a) 300-hPa Storm-tracks (ERA)

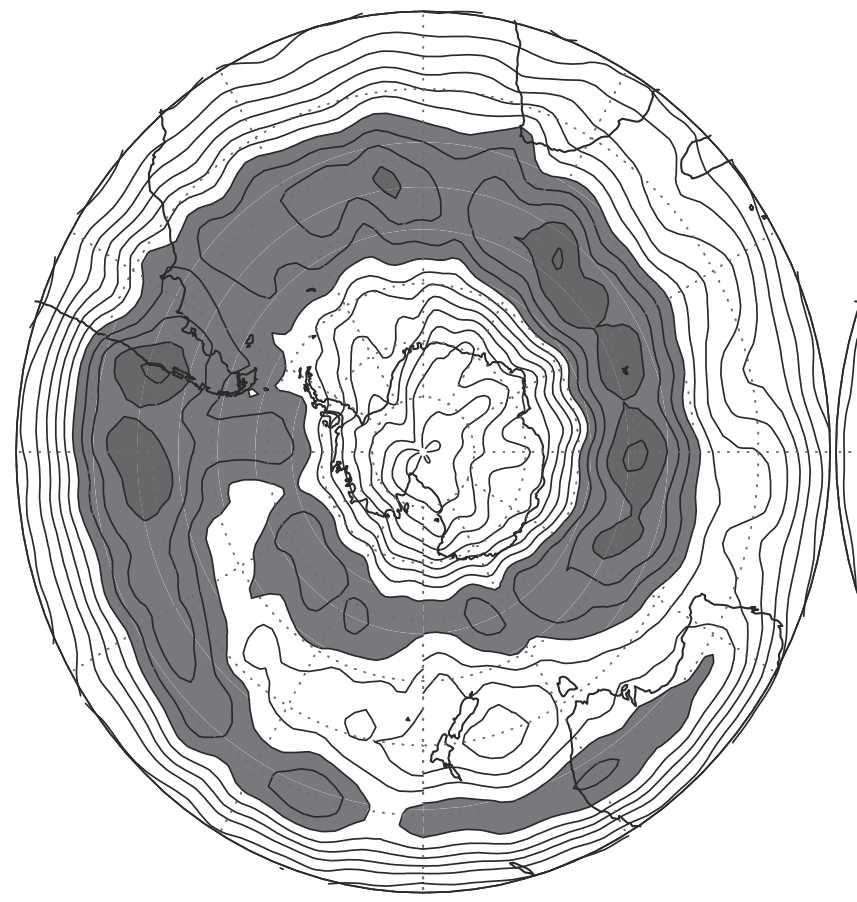

(b) 300-hPa Storm-tracks (NCEP)

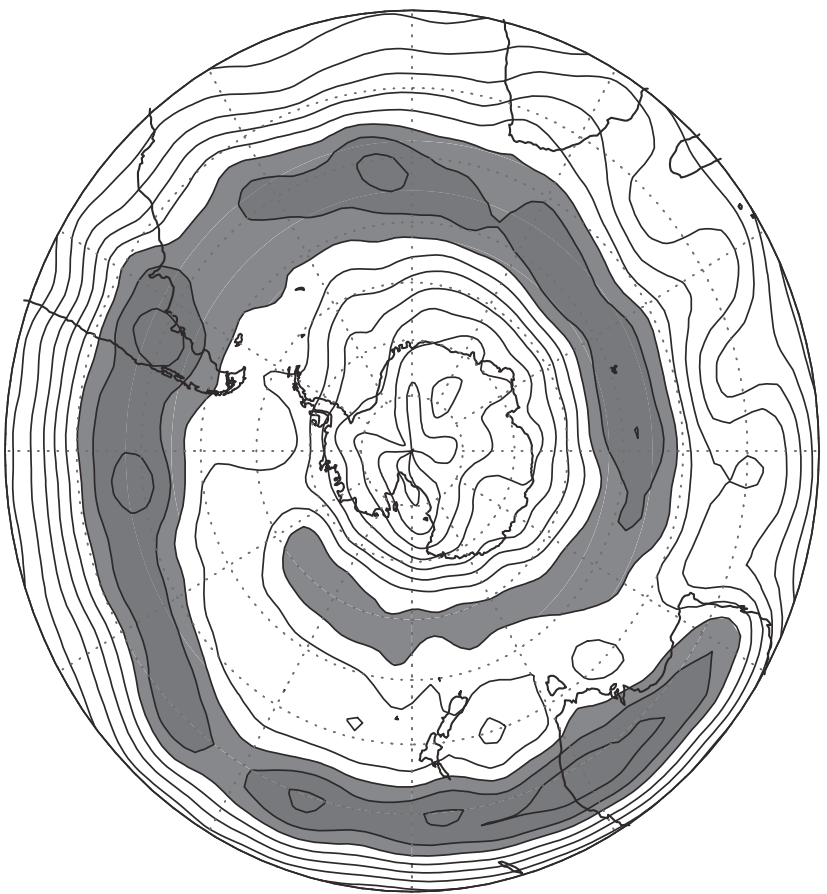

(c) $850-\mathrm{hPa}$ meridional heat fluxes (ERA)

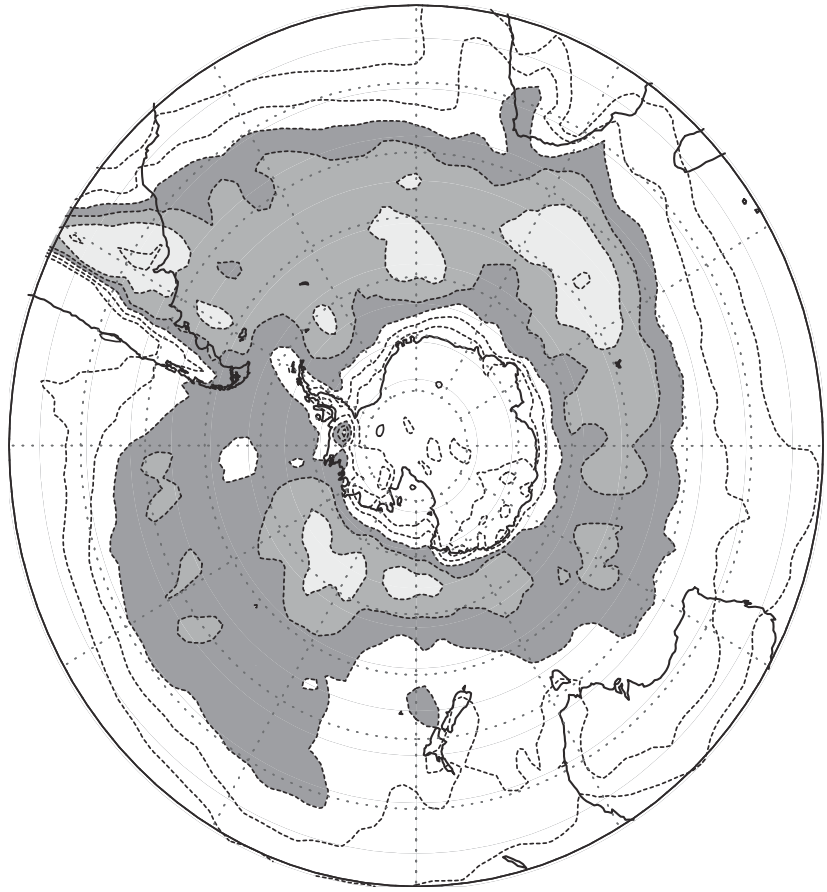

(d) 850-hPa meridional heat fluxes (NCEP)

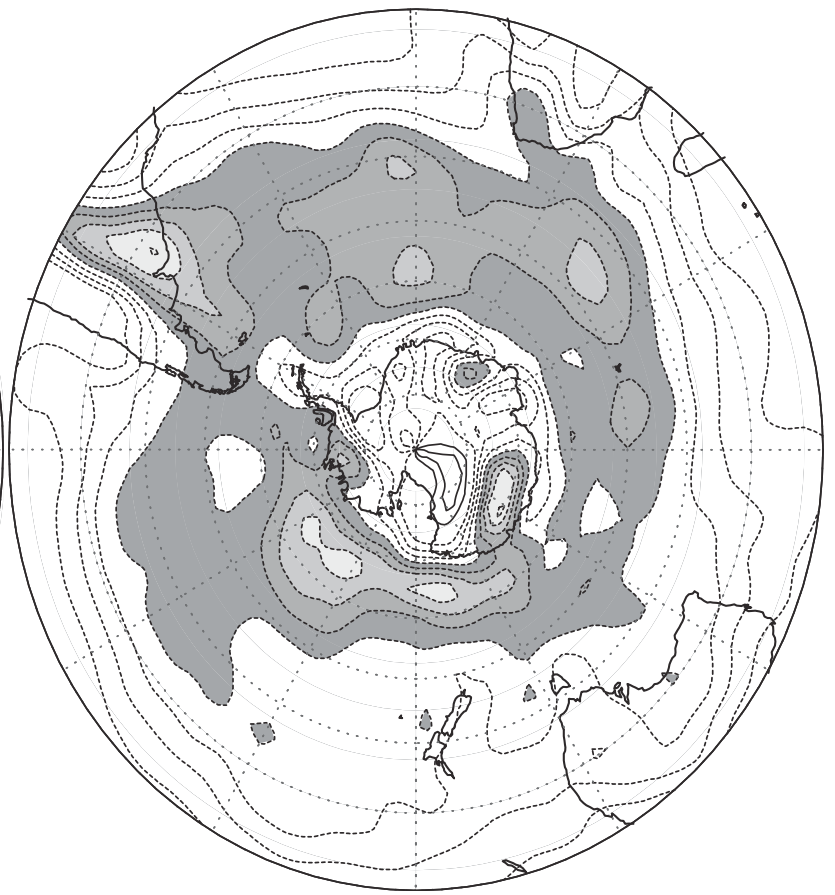

Figure 1. Standard deviation of 300-hPa eddy meridional wind component from (a) ERA and (b) from NCEP reanalyses. Contour interval is $1 \mathrm{~m} \mathrm{~s}^{-1}$, values larger than (a) $16 \mathrm{~m} \mathrm{~s}^{-1}$ and (b) $13 \mathrm{~m} \mathrm{~s}^{-1}$ are shaded. 850-hPa meridional heat fluxes from (c) ERA and (d) from NCEP reanalyses. Contour interval is (a) $5^{\circ} \mathrm{K} \mathrm{m} \mathrm{s}^{-1}$ and (b) $3^{\circ} \mathrm{K} \mathrm{m} \mathrm{s}^{-1}$. Values smaller than (a) $-15^{\circ} \mathrm{K} \mathrm{m} \mathrm{s}^{-1}$ and (b) $-12^{\circ} \mathrm{K} \mathrm{m} \mathrm{s}^{-1}$ are shaded. 

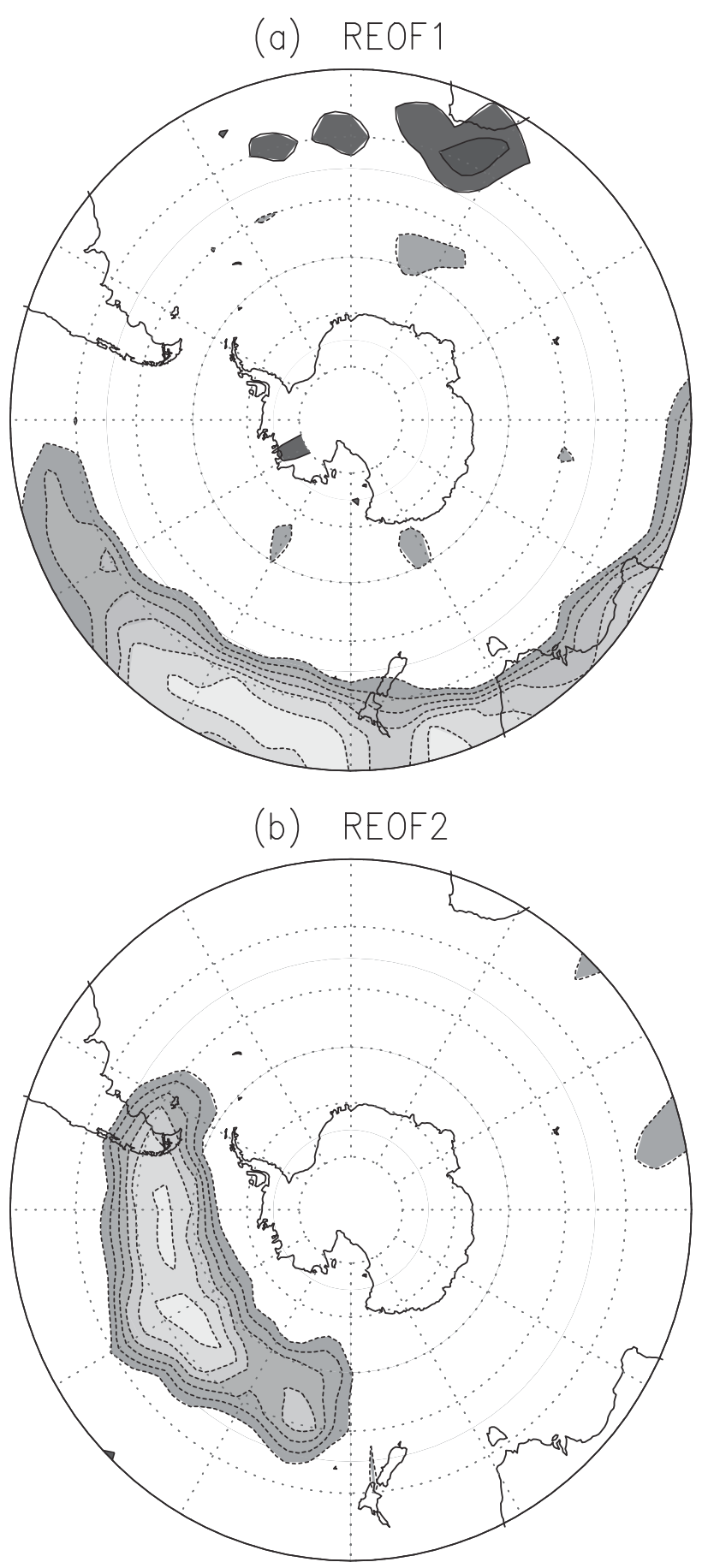

Figure 2. Factor loadings of (a) REOF 1 and (b) REOF 2 of storm-track anomalies as defined on text. Contour interval is 0.1 and values greater in magnitude than 0.3 are shaded.

NCEP reanalyses. Figure 2 display the two leading modes for the period from 1965 to 1999 that are basically the same to those previously obtained for the 15 -year period. The REOF1, which explains $10 \%$ of the variance, represents the storm-track variation equatorward of $40^{\circ} \mathrm{S}$ between west of Australia and West Coast of South America (Figure 2a). The REOF2, which explains $8 \%$ of the variance is associated with storm-tracks changes poleward of $40^{\circ} \mathrm{S}$ between $180^{\circ}$ and $50^{\circ} \mathrm{W}$ with maximum factor loadings westward of the southern tip of South America. The stability of both patterns was checked repeating the calculations over different periods. It was found that the first mode was always the same one. However, for periods between 1948 and 1960, the second mode (Figure 2b) changes to be the third while the new second mode was associated with changes over the Indian Ocean. Due to the fact that available observations during those early periods are very few at middle and high SH latitudes and the resulting NCEP reanalyses are more dependent on numerical model features, it was decided to not include those periods in the calculations and consider the results for the period between 1965 and 1999 as the most reliable and robust.

[9] Figure 3 shows that the temporal coefficient series of the two leading REOFs exhibit variability on interannual and longer time scales. Hence, both temporal coefficient series were decomposed through a harmonic analysis in two time series, the REOF-IA which includes the mode variability in the interannual range (periods between 2 and 6 years) and the REOF-ID which includes the interdecadal range (periods longer than 7 years). Figure 3 a shows the principal components for REOF1 and the associated two new series. It can be observed that REOF1-IA that represents $74 \%$ of the principal component variability has a strong connection with the occurrence of warm ENSO phases. On the other hand, REOF2-IA, that represents $56 \%$ of the corresponding principal component variance, does not exhibit a clear link with well-known interannual changes of the tropical Pacific SST (Figure 3b). In addition, it is noticeable the interdecadal variation of the second mode that are well described by the REOF2-ID series and which represents $44 \%$ of the variance. In particular, it can be observed a sign change of the REOF2-ID values around 1976 , year that several authors have identified with interdecadal changes on tropical sea surface temperature (SST) and on atmospheric circulation [e.g., Graham, 1994].

\subsection{Subtropical Pattern of Storm-Track Variation}

[10] The 500-hPa geopotential-height anomalies regressed upon REOF1-IA (Figure 4a) exhibit a wave train extending from low latitudes around $140^{\circ} \mathrm{W}$ toward the southeast Pacific and evidences of a wave number 3 in middle latitudes with large amplitudes in the Pacific-South America sector. This structure, usually called as Pacific-South America pattern (PSA) has been identified by many authors as the typical atmospheric response to equatorial anomalous heating during ENSO warm events [e.g., Karoly, 1989]. Also PSA is one of the leading SH circulation patterns on intraseasonal [Mo and Higgins, 1998] and on interannual [Kidson, 1999] time scales. The most remarkable feature of the PSA pattern is a strong anticyclonic anomaly at $60^{\circ} \mathrm{S}$, west of the Antarctic Peninsula (Figure 4a). This center has been associated to an increased number of blocking episodes during warm phases of ENSO [Renwick, 1998] that produce enhanced precipitation over central Chile [Rutllant and Fuenzalida, 1991] and subtropical South America [Grimm et al., 2000]. In agreement, the regression of July precipitation fields onto REOF1IA (Figure 5c) shows positive anomalies over those two regions while over the southern tip of South America, Antarctic Peninsula and over western subtropical Pacific, 

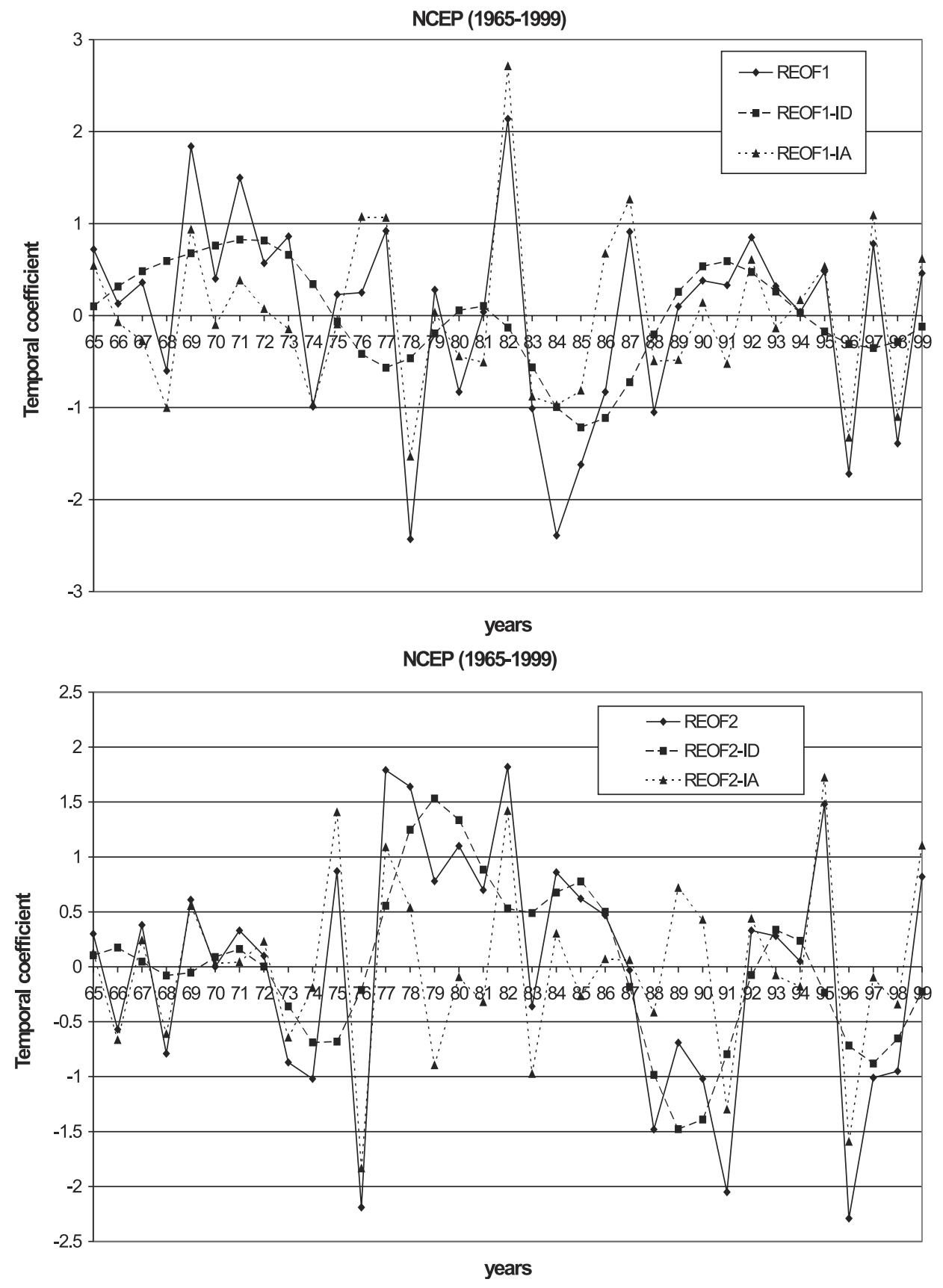

Figure 3. (a) Series of REOF 1 normalized temporal coefficient, REOF1-IA and REOF1-ID as defined on text. (b) idem (a) for REOF2.

drier than normal conditions are observed. The SST fields regressed upon REOF1-IA (Figure 5d) shows a strong positive signal around the equatorial Pacific and negative sign at subtropical latitudes, typical feature of ENSO events [Garreaud and Battisti, 1999]. However, it is remarkable that the highest SST regression values are found over central equatorial Pacific (west of $120^{\circ} \mathrm{W}$ ), indicating that storm-tracks variations on interannual time scales are mainly controlled by the ENSO cycle over that region. This result seems reasonable as the Rossby wave response to equatorial anomalous heating emanates from that region (Figure 4a), as it was previously discussed.
[11] The regression of $300-\mathrm{hPa}$ storm-track anomalies onto REOF1-IA series (figure not shown) resembles REOF1 pattern (Figure 2a) and it expresses negative storm-track anomalies over South Pacific subtropical regions and positive ones along South Pacific subpolar regions. It is not clear yet why during ENSO warm-events a weakening of synoptic-scale variability happens at South Pacific subtropical latitudes. An analysis of the monthly mean zonal winds regressed onto REOF1-IA (figures not shown) showed an intensification of the Pacific subtropical jet at upper levels as it is typical of ENSO warm events. As a consequence, an enhance of the mean baroclinic conditions, that favors 
(a) <REOF1-IA, Z' $(500 \mathrm{hPa})>$
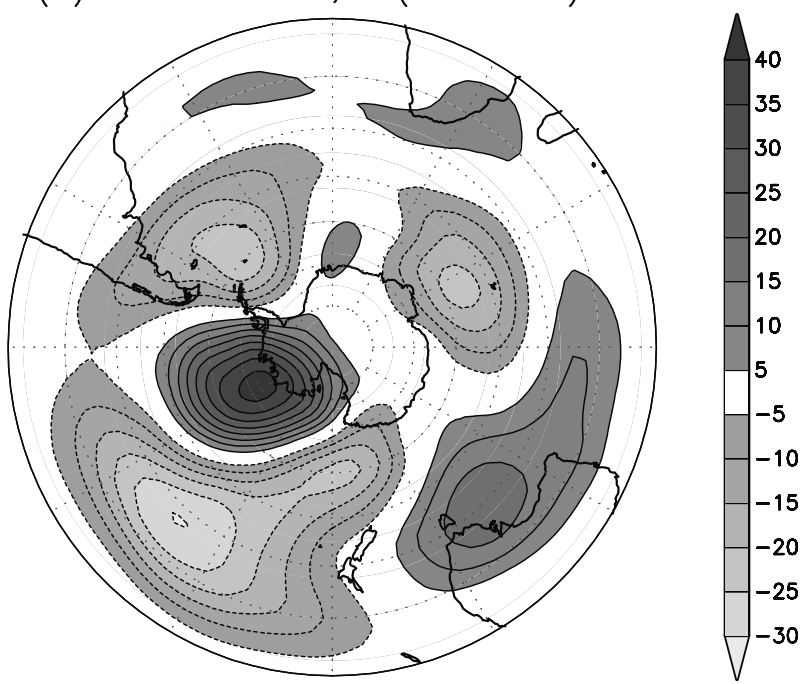

(b) $\left\langle\right.$ REOF $1-I D, Z^{\prime}(500 \mathrm{hPa})>$

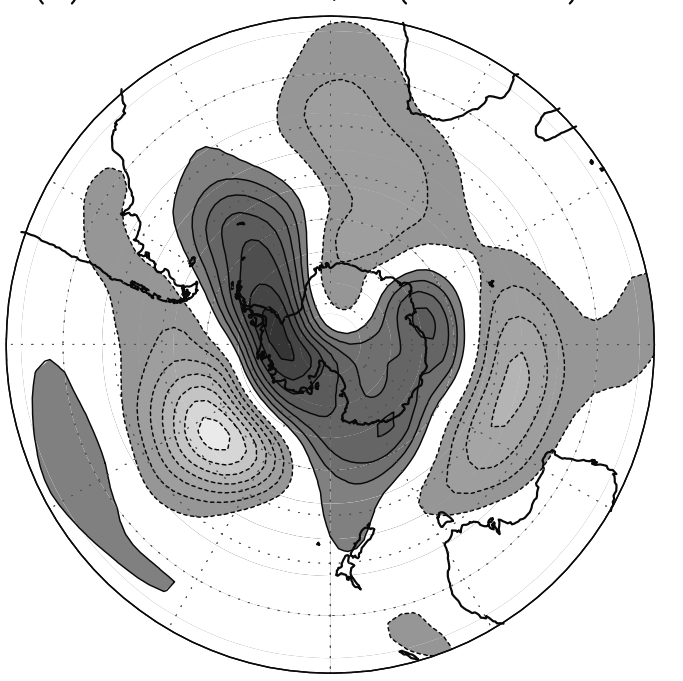

(c) <REOF1-IA, v' $T^{\prime}(850 \mathrm{hPa})>$

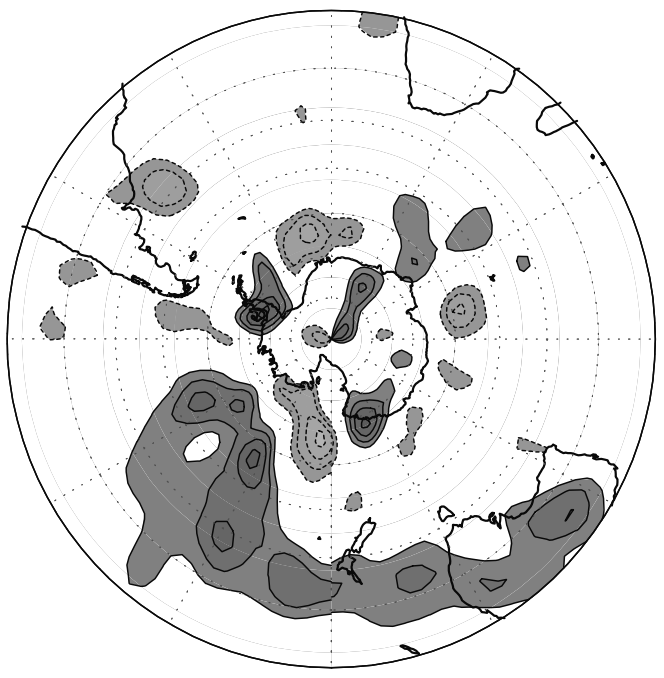

the generation of synoptic-scale waves, occurs over those regions (not shown) in agreement with Sinclair et al. [1997], who found there an increased number of cyclones during warm events. However, it is hypothesized that the intensified upper-level subtropical jet produces faster than normal eastward wave advection. Thus, baroclinic waves spend less time over regions with enhanced mean baroclinicity and attain smaller amplitudes. In addition, Figure 4c shows that low-level eddy meridional heat fluxes related with REOF1-IA present positive values over western subtropical Pacific suggesting a weaker wave growth by baroclinic conversions.

[12] We now investigate the spatial signatures associated with the interdecadal variability of the REOF 1 . The 300$\mathrm{hPa}$ storm-tracks regressed upon REOF-1D are negative over west and central subtropical Pacific (not shown) and they are related with negative regressed SST values over the subtropical portions of the southeast Pacific, south Atlantic and south Indian Ocean and positive ones over southwest subtropical Pacific (Figure 5d). Venegas et al. [1998] have suggested the existence of a similar global pattern of SST interdecadal variability with anticyclonic propagation of the anomalies inside the basins. Evidences of a Rossby wave train extending from the southeast Pacific toward the Atlantic are observed in the $500-\mathrm{hPa}$ geopotential height regression onto REOF1-ID (Figure 4b). A cyclonic anomaly at around $130^{\circ} \mathrm{W}, 60^{\circ} \mathrm{S}$ and a meridionally elongated anticyclonic anomaly over the Antarctic Peninsula are the most distinctive features of that interdecadal pattern. Garreaud and Battisti [1999] performed a study of the spatial signatures associated with an interdecadal mode, previously identified by Zhang et al. [1997] on global monthly SST anomalies for 1958-1996 period, and they obtain a similar feature on geopotential-height anomalies (their Figure 3). Furthermore, enhanced (decreased) precipitation is observed over eastern (western) subtropical South America associated with this interdecadal stormtrack variability. Montecinos et al. [2000] have found similar features over South America related to interdecadal changes of the tropical Pacific SST.

\subsection{Subpolar Pattern of Storm-Track Variation}

[13] The regression of $300-\mathrm{hPa}$ storm-tracks onto REOF2-IA resembles the REOF2 pattern (Figure $2 b$ ) with negative values over the southeast Pacific between $60^{\circ} \mathrm{S}$ and $50^{\circ} \mathrm{S}$ and positive values extending further north. This latitudinal shift of the synoptic-scale activity is associated with positive (negative) regressed values of low-level eddy meridional heat transports at middle (subtropical) latitudes of the south Pacific Ocean (Figure 6c), indicating interannual changes on the baroclinic structure of synoptic waves.

[14] The spatial structure of the REOF2 interannual signature on the SST field (Figure 7) is mainly characterized by a negative center over the southwest Pacific, between $40^{\circ} \mathrm{S}$ and $20^{\circ} \mathrm{S}$. Also, indications of a Rossby wave train extending from the southeast Pacific toward the Atlantic are

Figure 4. (opposite) 500-hPa geopotential height monthly anomalies regressed upon (a) REOF1-IA and (b) REOF1ID. Contour interval is $5 \mathrm{~m}$ and zero contour is omitted. (c) $850-\mathrm{hPa}$ meridional heat fluxes regressed onto REOF1-IA. Contour interval is $0.5^{\circ} \mathrm{K} \mathrm{m} \mathrm{s}^{-1}$ and zero contour is omitted. 

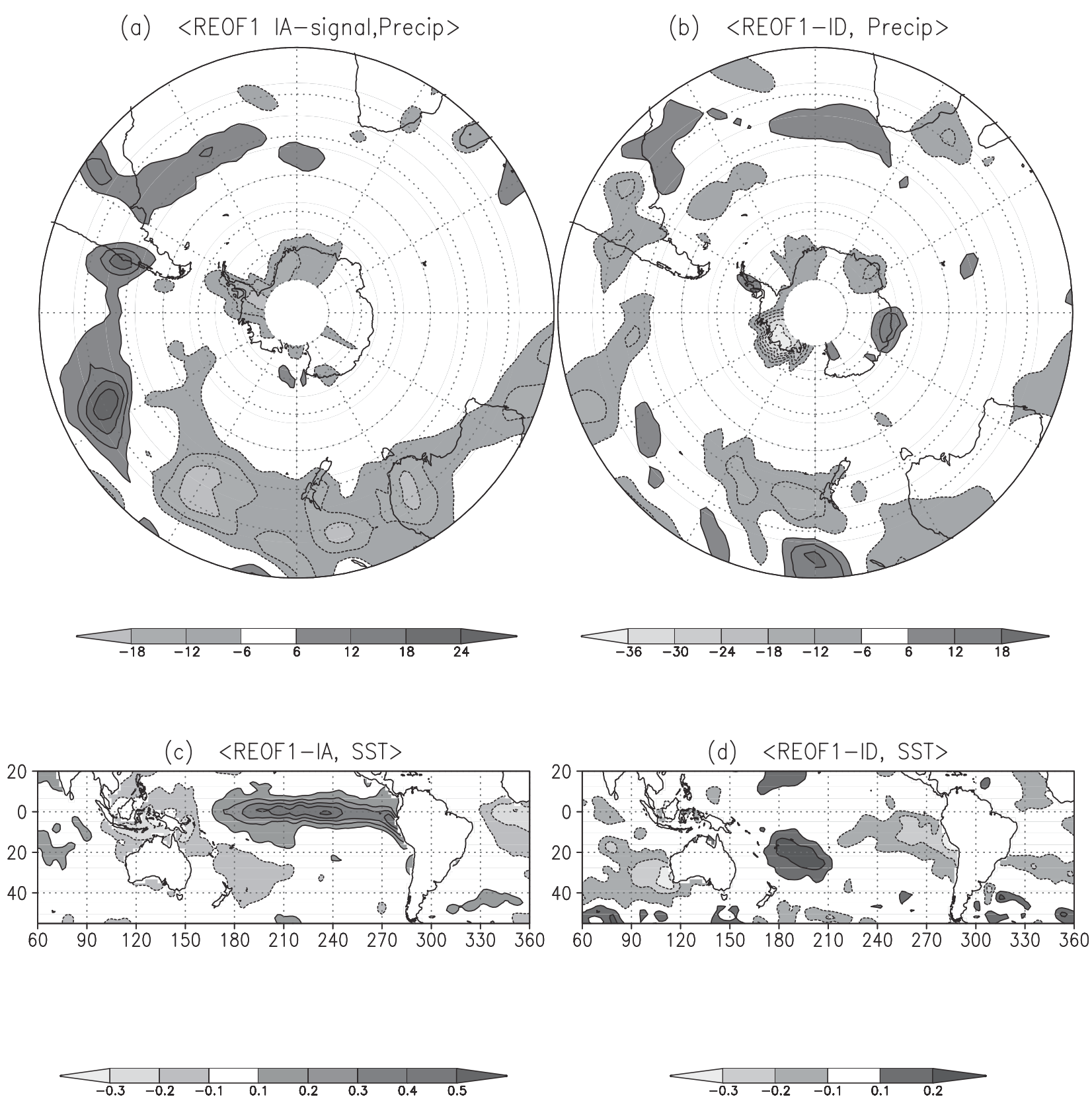

Figure 5. Precipitation anomalies regressed onto (a) REOF1-IA and (b) REOF1-ID. Contour interval is $6 \mathrm{~mm}$ and zero contour is omitted. SST anomalies regressed upon (c) REOF1-IA and (d) REOF1-ID. Contour interval is $0.1^{\circ} \mathrm{K}$ and zero contour is omitted.

observed (Figure 6a) but this wave train is different from that associated with the ENSO-like interannual variability of the REOF1 (Figure 4a).

[15] The interdecadal variation of REOF2, as it was previously mentioned in section 3.2 , contributes to the pattern temporal variability as much as the interannual variation. Its spatial signature on the upper-level stormtracks is associated with a generalized decrease of the highfrequency atmospheric activity along the middle latitudes of the whole SH (not shown). The regression of the $500-\mathrm{hPa}$ geopotential heights onto the REOF2-ID (Figure 6b) is largely dominated over Antarctica by the high-latitude mode (HLM) [e.g., Mo and White, 1985] that has a high degree of zonal symmetry with opposite signs between polar and middle latitudes. Also, signs of a wave number 3 are observed at middle latitudes, in agreement with the leading mode of $\mathrm{SH}$ winter circulation variation identified by Kidson [1999] on interannual time scales. Chen and Yen [1997] found that interdecadal changes of cyclone activity are associated with a wave number 3 pattern. The regression of SST anomalies onto REOF2-ID showed no significant values over any of the ocean basins (not shown). In agreement, Kidson and Waterson [1999] and Carril and Navarra [2001] have suggested that the HLM seems to be an internal atmospheric extratropical oscillation triggered by changes in the eddy momentum flux convergence. 
(a) $<$ REOF2-IA, Z'(500 hPa)>
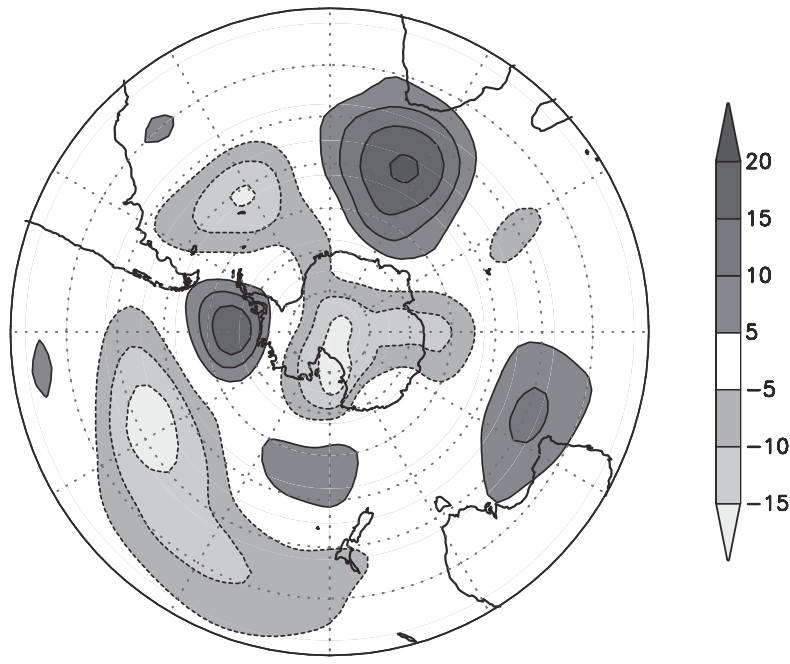

(b) $<$ REOF2-ID, Z'(500 hPa)>
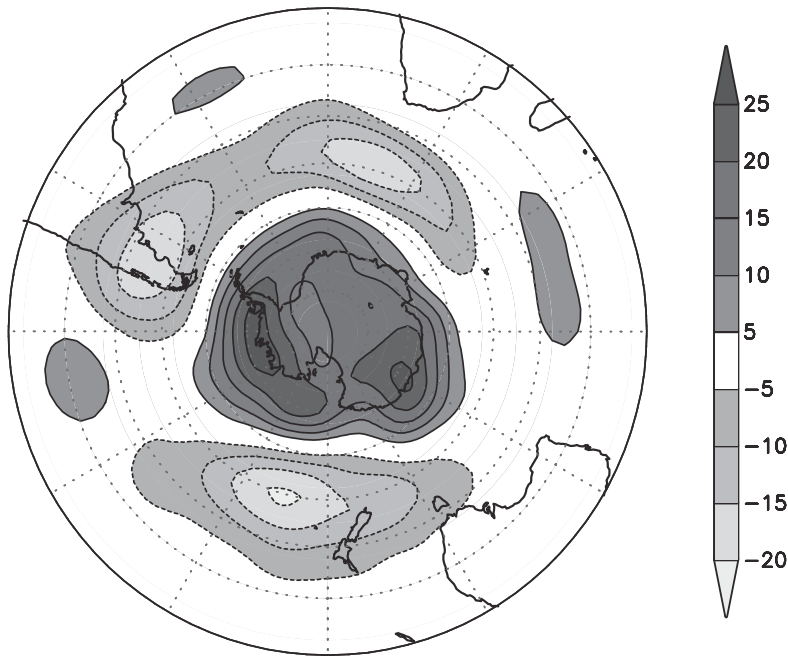

(c) <REOF2-IA, V'T'(850 hPa)>

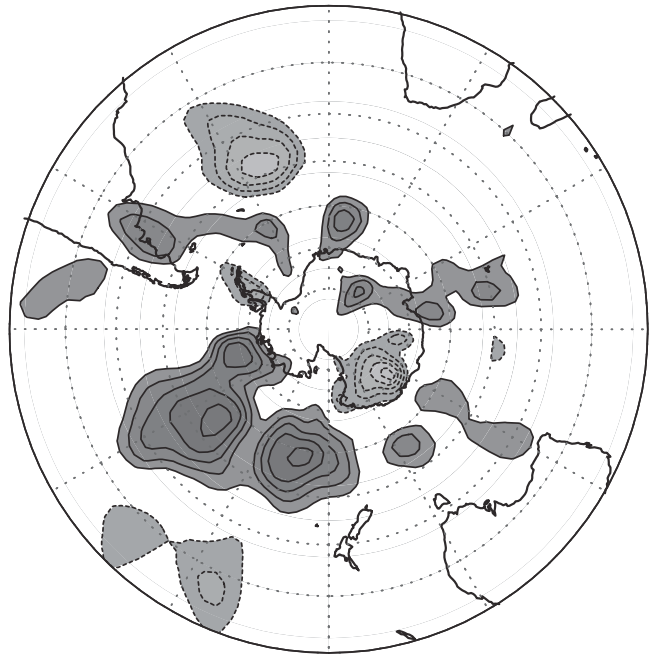

[16] Finally, it can be pointed out that the regressions of the precipitation fields onto both REOF2-IA and REOF2-ID were also performed and both present positive anomalies over both coasts of subtropical South America (not shown). In agreement, Barros and Silvestri [2001] have recently shown precipitation changes over subtropical South America, related to variations of the subtropical Pacific SST and also to HLM phases. However, this subject deserves more attention as there are very few researches linking precipitation over South America and other sources of lowfrequency variability besides ENSO.

\section{Conclusions}

[17] In this paper we have documented the low-frequency variations of the atmospheric synoptic-scale variability (210 days) at the Southern Hemisphere, during austral winter. Regions where such variability maximizes are known as storm-tracks. Therefore, an REOF analysis was applied to July storm-track anomalies for 1965-1999 period using NCEP reanalyses and our major results are the following:

1. The SH winter storm-track exhibits two leading modes of year-to-year variations: the REOF1 associated with changes along subtropical latitudes from the Indian to the Pacific Ocean and the REOF2 which concentrates its activity south of $40^{\circ} \mathrm{S}$ along the southeast Pacific. Both leading modes exhibit significant variability on interannual (2-7 years) and interdecadal (longer than 7 years) time scales.

2. The interannual variation of the REOF1 exhibits a close relationship with ENSO variability. The corresponding signal on SST anomalies shows a conspicuous maximum over central equatorial Pacific, in agreement with several authors who showed that ENSO remote signal at middle and high latitudes emerges from SST changes at those regions. Accordingly, the interannual signature of REOF1 on geopotential-height anomalies shows the typical PSA pattern characterized by a Rossby wave train propagating poleward from the tropics.

3. On interdecadal time scales, the REOF1 is related to SST anomalies over the subtropical portions of the Pacific, Atlantic and Indian Oceans, resembling patterns of SST decadal variations already identified by other authors. In particular, the interdecadal variability of the REOF1 is expressed in the $\mathrm{SH}$ winter circulation as a Rossby wave train different from the PSA with strongest signals over the southeast Pacific and the Antarctic Peninsula.

4. The REOF2 that represents storm-track changes west of the Antarctic Peninsula also exhibits low-frequency variations but they are not related to ENSO variability. While on interannual scales, the REOF2 is related to SST anomalies over western Pacific between $40^{\circ} \mathrm{S}$ and $20^{\circ} \mathrm{S}$, on interdecadal time scales it seems to not be significantly related to SST changes in any of the basins. In particular, the spatial signature of the REOF2 interdecadal variability on

Figure 6. (opposite) 500-hPa geopotential height monthly anomalies regressed upon (a) REOF2-IA and (b) REOF2ID. Contour interval is $5 \mathrm{~m}$ and zero contour is omitted. (c) $850-\mathrm{hPa}$ meridional heat fluxes regressed onto REOF2-IA. Contour interval is $0.5^{\circ} \mathrm{K} \mathrm{m} \mathrm{s}^{-1}$ and zero contour is omitted. 


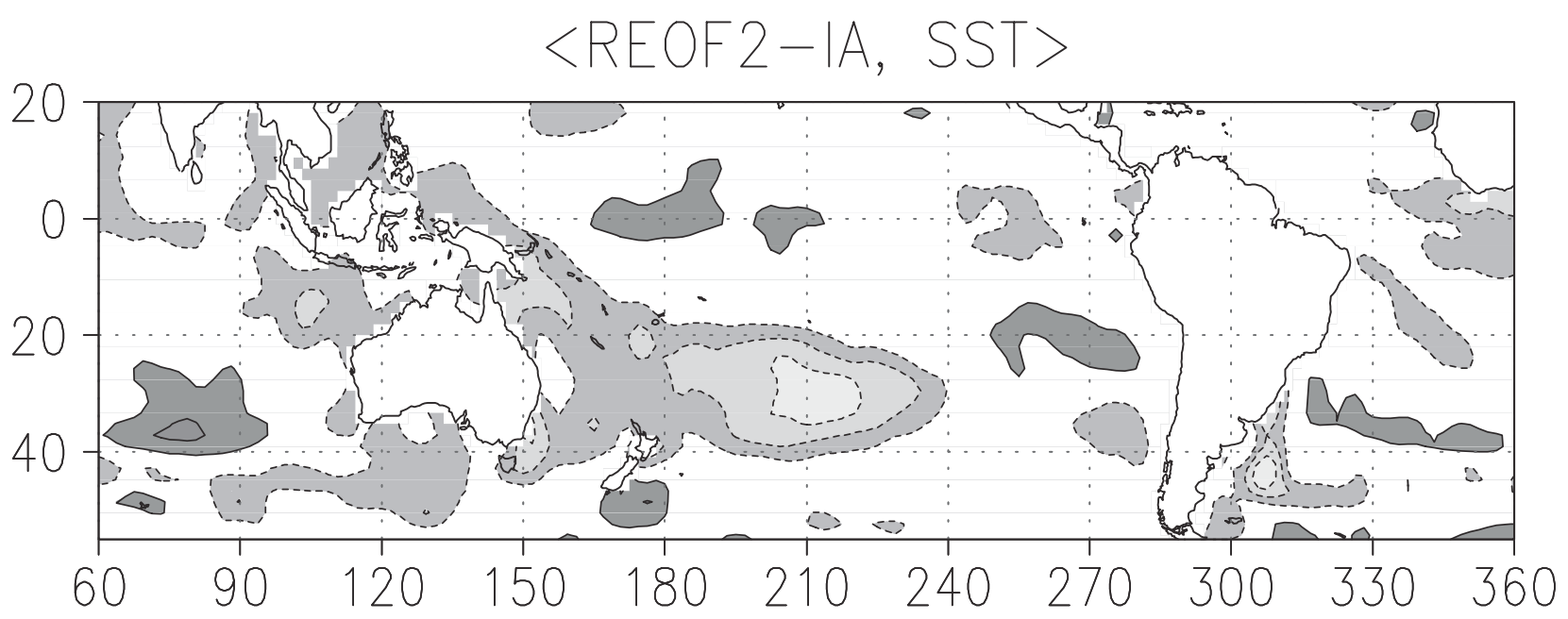

\begin{tabular}{l|lll|l|l}
\hline & & & & & \\
\hline-0.3 & -0.2 & -0.1 & 0.1 & 0.2
\end{tabular}

Figure 7. SST anomalies regressed upon REOF2-IA. Contour interval is $0.1^{\circ} \mathrm{K}$ and zero contour is omitted.

the SH circulation is characterized by the well-known high latitude mode characterized by a monopole over the Antarctica and a 3-wave pattern at middle latitudes.

5. Further research is required to better describe the changes on the $\mathrm{SH}$ baroclinic wave dynamics produced by the low-frequency patterns identified here. In addition, the nature of both interannual and interdecadal signals of REOF2 are beyond the scope of this paper but certainly needs to be further explored. In particular, possible relationships of these patterns with SST variations over the southern oceans should be considered as it was not performed in this paper due to a lack of sufficient SST data south of $50^{\circ} \mathrm{S}$.

[18] Acknowledgments. This work was supported by UBA grant X072 and ANPCyT PICT-99 7-6335. ERA reanalyses are available at CIMA from LBA Program. NCEP reanalysis, SST and CMAP data sets were provided through NOAA Climate Diagnostic Center (http:// www.cdc.noaa.gov). Helpful comments and suggestions from two anonymous reviewers are greatly appreciated.

\section{References}

Barros, V., and G. Silvestri, On the relation between sea surface temperature at the subtropical south-central Pacific and precipitation in southeastern South America, J. Clim., in press, 2001.

Berbery, E. H., and C. S. Vera, Characteristics of the Southern Hemisphere winter storm track with filtered and unfiltered data, J. Atmos. Sci., 53, 468-481, 1996.

Carril, A., and A. Navarra, The interannual leading modes of the extratropical variability in the Southern Hemisphere simulated by the ECHAM-4 atmospheric model, Clim. Dyn., in press, 2001.

Chen, T.-C., and M. C. Yen, Interdecadal variation of the Southern Hemisphere circulation, J. Clim., 10, 805-811, 1997.
Folland, C. K., and D. E. Parker, Correction of instrumental biases in historical sea surface temperature data, Q. J. R. Meteorol. Soc., 121, 319-367, 1995

Garreaud, R. D., and D. S. Battisti, Interannual (ENSO) and interdecadal (ENSO-like) variability in the Southern Hemisphere tropospheric circulation, J. Clim., 12, 2113-2123, 1999.

Graham, N. E., Decadal-scale climate variability in the 1970s and 1980s: Observations and model results, Clim. Dyn., 10, 135-162, 1994.

Grimm, A., V. Barros, and M. Doyle, Climate variability in southern South America associated with El Niño and La Niña events, J. Clim., 13, 35$58,2000$.

Kalnay, E. M., et al., The NCEP/NCAR reanalysis project, Bull. Am. Meteorol. Soc., 77, 437-471, 1996.

Karoly, D. J., Southern Hemisphere circulation features associated with El Niño-Southern Oscillation, J. Clim., 2, 1239-1252, 1989.

Kidson, J. W., Principal modes of Southern Hemisphere low-frequency variability obtained from NCEP-NCAR reanalyses, J. Clim., 12, 2808$2830,1999$.

Kidson, J. W., and I. G. Waterson, The structure and predictability of the high-latitude mode in the CSIRO9 general circulation model, J. Atmos. Sci., 56, 3859-3873, 1999.

Marshall, G. J., and J. C. King, Southern Hemisphere circulation anomalies associated with extreme Antarctic Peninsula winter temperatures, Geophys. Res. Lett., 25, 2437-2440, 1998.

Mo, K. C., and W. Higgins, The Pacific South America modes and the tropical intraseasonal oscillation, Mon. Weather Rev., 126, 1581-1596, 1998.

Mo, K. C., and G. H. White, Teleconnections in the Southern Hemipshere, Mon. Weather Rev., 113, 22-37, 1985.

Montecinos, A., A. Díaz, and P. Aceituno, Seasonal diagnostic and predictability of rainfall in subtropical South America based on tropical Pacific SST, J. Clim., 13, 746-758, 2000.

Renwick, J. A., ENSO-related variability in the frequency of South Pacific blocking, Mon. Weather Rev., 126, 3117-3123, 1998.

Reynolds, R. J., and T. M. Smith, Improved global sea surface temperature analyses using optimal interpolation, J. Clim., 7, 929-948, 1994.

Rutllant, J., and H. Fuenzalida, Synoptic aspects of the central Chile rainfall variability associated with the Southern Oscillation, Int. J. Climatol., 11, $63-76,1991$. 
Simmonds, I., and K. Keay, Mean Southern Hemisphere extratropical cyclone behavior in the 40-year NCEP-NCAR reanalysis, J. Clim., $13,873-885,2000 a$

Simmonds, I., and K. Keay, Variability of Southern Hemisphere extratropical cyclone behavior, 1958-1997, J. Clim., 13, 550-560, 2000b.

Sinclair, M. R., J. A. Renwick, and J. W. Kidson, Low-frequency variability of Southern Hemisphere sea level pressure and weather system activity, Mon. Weather Rev., 127, 2531-2542, 1997.

Solman, S. A., and C. C. Menendez, Interannual variability of winter storm tracks in the Southern Hemisphere, in 6th AMS International Conference on Southern Hemisphere Meteorology and Oceanography, pp. 40-42, Am. Meteorol. Soc., Boston, Mass., 2000.

Trenberth, K. E., Observed Southern Hemisphere eddy statistics at 500 $\mathrm{mb}$; Frequency and spatial dependence, J. Atmos. Sci., 38, 2585-2605, 1981.

Trenberth, K. E., Storm tracks in the Southern Hemisphere, J. Atmos. Sci., $48,2159-2178,1991$.
Venegas, S. A., L. A. Mysak, and D. N. Straub, An interdecadal climate cycle in the South Atlantic and its links to other ocean basins, J. Geophys. Res., 103(C11), 24,7233-24,736, 1998.

Vera, C. S., and P. K. Vigliarolo, A statistical-dynamical diagnostic of cold-air outbreaks over South America, Mon. Weather Rev., 128, 3-24, 2000.

Yuan, X., D. Martinson, and W. Liu, Effect of air-sea-ice interaction on winter 1996 southern ocean subpolar storm distribution, J. Geophys. Res., 104(D2), 1991-2007, 1999.

Zhang, Y. J., M. Wallace, and D. S. Battisti, ENSO-like interdecadal variability: 1900-1993, J. Clim., 10, 1004-1020, 1997.

C. Vera, CIMA. Pab. II/Department of Atmospheric and Ocean Sciences, University of Buenos Aires-CONICET, 2do. Piso, Ciudad Universitaria, 1428 Buenos Aires, Argentina. (carolina@at1.fcen.uba.ar) 